\title{
Maternal fatty acid status in pregnancy and childhood atopic manifestations: KOALA Birth Cohort Study
}

Citation for published version (APA):

Notenboom, M. L., Mommers, M., Jansen, E. H. J. M., Penders, J., \& Thijs, C. (2011). Maternal fatty acid status in pregnancy and childhood atopic manifestations: KOALA Birth Cohort Study. Clinical and Experimental Allergy, 41(3), 407-416. https://doi.org/10.1111/j.1365-2222.2010.03672.x

Document status and date:

Published: 01/03/2011

DOI:

10.1111/j.1365-2222.2010.03672.x

Document Version:

Publisher's PDF, also known as Version of record

Document license:

Taverne

Please check the document version of this publication:

- A submitted manuscript is the version of the article upon submission and before peer-review. There can be important differences between the submitted version and the official published version of record.

People interested in the research are advised to contact the author for the final version of the publication, or visit the DOI to the publisher's website.

- The final author version and the galley proof are versions of the publication after peer review.

- The final published version features the final layout of the paper including the volume, issue and page numbers.

Link to publication

\footnotetext{
General rights rights.

- You may freely distribute the URL identifying the publication in the public portal. please follow below link for the End User Agreement:

www.umlib.nl/taverne-license

Take down policy

If you believe that this document breaches copyright please contact us at:

repository@maastrichtuniversity.nl

providing details and we will investigate your claim.
}

Copyright and moral rights for the publications made accessible in the public portal are retained by the authors and/or other copyright owners and it is a condition of accessing publications that users recognise and abide by the legal requirements associated with these

- Users may download and print one copy of any publication from the public portal for the purpose of private study or research.

- You may not further distribute the material or use it for any profit-making activity or commercial gain

If the publication is distributed under the terms of Article $25 \mathrm{fa}$ of the Dutch Copyright Act, indicated by the "Taverne" license above, 


\title{
Maternal fatty acid status in pregnancy and childhood atopic manifestations: KOALA Birth Cohort Study
}

\author{
M. L. Notenboom ${ }^{1}$, M. Mommers ${ }^{1}$, E. H. J. M. Jansen ${ }^{2}$, J. Penders ${ }^{1,3}$ and C. Thijs ${ }^{1}$ \\ ${ }^{1}$ Department of Epidemiology, CAPHRI School of Public Health and Primary Care, Maastricht University, Maastricht, The Netherlands, ${ }^{2}$ Laboratory for Health \\ Protection Research, National Institute for Public Health and the Environment, Bilthoven, The Netherlands and ${ }^{3}$ Department of Medical Microbiology, Maastricht \\ University Medical Centre, Maastricht, The Netherlands
}

\section{Clinical \&t Experimental Allergy}

Correspondence:

C. Thijs, Department of Epidemiology, CAPHRI School of Public Health and Primary Care, Maastricht University, PO Box 616, 6200 MD Maastricht, The Netherlands.

E-mail: c.thijs@maastrichtuniversity.nl Cite this as: M. L. Notenboom, M. Mommers, E. H. J. M. Jansen, J. Penders and C. Thijs, Clinical \& Experimental Allergy, 2011 (41) 407-416.

\begin{abstract}
Summary
Background Prevalence of atopic disorders has increased rapidly, but aetiological factors responsible for this increase are still largely unknown. Prenatal exposure to a proinflammatory fatty acid status is hypothesized although little research has been carried out. Objective To investigate whether prenatal fatty acid exposures are associated with atopy in childhood.

Methods In the KOALA Birth Cohort Study, maternal blood samples $(n=1275)$ at 34-36 weeks of pregnancy were assayed for $n-6$ and n-3 long-chain polyunsaturated fatty acids (LCPs). The full spectrum of offspring atopic manifestations (wheeze, asthma, allergic rhinoconjunctivitis, eczema, atopic dermatitis, allergic sensitization, and high total IgE) until the age of 6-7 years was assessed by repeated parental questionnaires and measurements of total and specific IgE. Associations of maternal fatty acid status with child atopic outcomes were analysed using multivariable logistic regression and generalized estimating equations for repeated measurements.

Results High ratio of maternal n-6 vs. n-3 LCPs was associated with a lower risk of eczema in the child ( $P$ for trend 0.012). More specifically, we found a decreased risk of eczema in the first 7 months of life with increasing arachidonic acid levels ( $P$ for trend 0.013). No associations were found between maternal fatty acids and offspring airway-related atopic manifestations, sensitization, or high total IgE.

Conclusion and Clinical Relevance The development of atopic disorders in early childhood is associated with prenatal exposure to $n-6$ vs. $n-3$ fatty acids, but with inconsistencies between different manifestations. Further exploration of associations with maternal diet and genetic variants in genes regulating fatty acid metabolism are required. This study shows that the influence of prenatal exposure to fatty acids on the risk of eczema in the child is limited to the first year of life.
\end{abstract}

Keywords allergic rhinoconjunctivitis, atopic, atopy, bronchial asthma, cohort study, dermatitis, eczema, immunoglobulin E, polyunsaturated fatty acids, prenatal, wheeze Submitted 1 March 2010; revised 8 November 2010; accepted 15 November 2010

\section{Introduction}

The prevalence of bronchial asthma and related atopic diseases, such as eczema and allergic rhinoconjunctivitis, has increased rapidly over the last decades. With an estimated 30\% of children in western societies affected, atopic disorders are an important public health problem [1].

In 1997, Black and Sharpe [2] proposed a hypothesis, linking the increased risk of asthma and atopic diseases to changes in dietary fat intake, notably an increased intake of margarine and vegetable oils ( $\omega-6$ polyunsaturated fatty acid, n-6 PUFA) and a decreased intake of oily fish, rich in $\omega-3$ polyunsaturated fatty acid (n-3 PUFA). n-6 PUFAs are mainly consumed in the form of the essential fatty acid linoleic acid (LA, 18:2 n-6), which is a precursor for arachidonic acid (AA, $20: 4 n-6)$. AA in turn is a precursor for strong acting pro-inflammatory $\omega-6$ eicosanoids, like prostaglandin E2 and leukotriene B4, 
which inhibit T helper 1 cytokine responses and enhance IgE production [3]. n-3 PUFAs, like the essential fatty acid $\alpha$-linolenic acid (ALA, 18:3 n-3) and n-3 long-chain polyunsaturated fatty acids (LCPs), reduce the formation of AA by competitive metabolism with LA for the need of the 86 -desaturase enzyme, the rate-limiting step in the desaturation to $n-3$ and n-6 LCPs. In addition, the n-3 LCPs eicosapentaenoic acid (EPA, 20:5 n-3) and docosahexaenoic acid (DHA, 22:6n-3) reduce the AA amount available for synthesis of eicosanoids by replacing AA in the membranes of inflammatory cells and reducing cyclooxygenase 2 (COX-2) gene expression and inhibition of COX-2 activity. Therefore, it is hypothesized that the decreased dietary intake of oily fish results in less inhibition of the pro-inflammatory AA pathway, increasing the likelihood of an atopic reaction [4-6].

As stated by Sala-Vila et al. [7] and recently confirmed by Miyake et al. [8] in a large cohort study, several studies showed protective effects of a diet rich in fish for several atopic outcomes, but fatty acid supplementation trials in existing atopy generally showed disappointing results [9]. On the other hand, children who develop atopy already have an altered immune response at birth, and atopy may thus be determined in early life or even by factors acting in utero [10]. Therefore, PUFAs may play an aetiological role prenatally. Because the foetus is entirely dependent on maternal fatty acid supply, the maternal fatty acid status could be an important factor for the development of atopic disease in the child [11].

In the current study, we assessed the relationship between maternal fatty acid status in pregnancy and atopic manifestations in their children until the age of 6-7 years. Our study contributes to current knowledge due to the quantified levels of fatty acids, the large study population, and the full spectrum of childhood atopic and related manifestations. We anticipated that the influence of maternal fatty acid status would wane over time, because as the child grows older its fatty acid status is increasingly determined by his own diet. Therefore, we focused on wheeze, eczema, and IgE in the first 2 years, and tested for age dependency in longitudinal analyses of repeated measurements of atopic outcomes.

\section{Methods}

\section{Study population and data collection}

This birth cohort study is embedded in the KOALA Birth Cohort Study, the Netherlands. A detailed description of the design has been provided elsewhere [12]. In brief, participants were recruited from October 2000 onwards. Healthy pregnant women with a conventional lifestyle $(n=2343)$ were recruited from an ongoing prospective cohort study on pregnancy-related pelvic girdle pain [13], and pregnant women with an alternative lifestyle $(n=491)$ were recruited through several 'alternative' channels, like organic food shops, anthroposophist doctor's practices, and Steiner schools.

The present study population consists of participants recruited from January 2002 onwards who consented to biosampling. Maternal blood samples $(n=1374)$ were taken in the 34th-36th week of pregnancy and venous blood samples from their offspring at age 24 months $(n=815)$. Information on determinants of atopy as well as on atopic outcomes were collected by repeated parental questionnaires at 34 weeks of pregnancy and when the children were aged 3, 7, 12, 24 months, $4-5$ years, and 6-7 years. At the age of 24 months, children were examined for manifestations of atopic dermatitis $(\mathrm{AD})$ by a trained nurse during a home-visit.

Exclusion criteria were missing data on maternal fatty acid status, multiple pregnancy, prematurity (gestational age $<37$ weeks), congenital abnormalities, and no response to all the questionnaires in first 12 months postpartum. The study was approved by the Medical Ethical Committee of the Maastricht University Medical Centre $(\mathrm{MUMC}+)$. All parents gave written informed consent.

\section{Maternal fatty acid status}

Maternal blood was collected in EDTA tubes at 34-36 weeks of pregnancy. We assessed maternal fatty acid status in plasma phospholipids. After centrifugation, the EDTA plasma was stored in cryovials at $-80^{\circ} \mathrm{C}$. Subsequently, the plasma was deproteinated and the precipitate was removed by centrifugation before further analysis. A fatty acid methyl ester sample (FAME sample) was obtained according to a standardized protocol, wherein the sample was eluted, hydrolyzed, and methylated. Hexane was added and the FAME sample was separated using a GC-3900 gas chromatograph (Varian Inc., Middelburg, the Netherlands) equipped with a CP 8400 auto injector. Galaxie software (Varian Inc.) was used for quantization and identification of peaks. Fatty acid concentrations are expressed as proportion of total fatty acids (C14-C22) present in the chromatogram (weight percentage, wto).

In line with Black and Sharpe's hypothesis, we examined whether high prenatal $n-6$ fatty acid exposure (AA) is associated with an increased risk of atopic disease, and whether high exposure to $n-3$ fatty acids (sum of EPA, DPA $\mathrm{n}-3$, and DHA) is associated with decreased risk. Furthermore, we examined whether imbalanced $n-6$ to $n-3$ ratios (high ratio of LA to ALA) and high ratio of n-6 LCPs (sum of DGLA and AA) to n-3 LCPs (sum of EPA, DPA n-3, and DHA) were associated with increased risk of atopic disease.

\section{Outcome measures}

The questionnaires, filled out by parents at each followup, contained questions about atopic symptoms adapted from the International Study of Asthma and Allergies 
Questionnaire (ISAAC) [14]. 'Wheeze' was defined as parents-report of wheezing or whistling in the chest since last follow-up moment for questionnaires in the first year of life (3, 7, and 12 months) and in the last 12 months for questionnaires after the first year of life (24 months, 4-5 years, and 6-7 years). 'Asthma' was defined as ever doctordiagnosed bronchial asthma with clinical symptoms, and/or the use of prophylactic medication in the last 12 months at the age of 6-7 years. Clinical symptoms were defined as at least one attack of wheeze or dyspnoea. Prophylactic medication was defined as regular use of short-acting bronchodilators or the use of inhaled corticosteroids or subsequent medication conform the Dutch guidelines of treatment of bronchial asthma in children [15]. Regular use was defined as every day use for a period of at least 2 months or use associated with physical activity of the child.

'Allergic rhinoconjunctivitis' at age 6-7 years was defined as nose problems (sneezing, a runny nose, or a blocked nose) when the child did not have a cold or the flu, accompanied by itchy watery eyes, as adapted from the ISAAC questionnaire, in combination with medication against hayfever. Prophylactic medication (local antihistamines, oral antihistamines, local corticosteroids) or subsequent medication steps according to the Dutch general practice guidelines for the treatment of allergic rhinitis [16] for hayfever-related complaints were regarded as medication against hayfever.

'Eczema' was assessed by questions adapted from the ISAAC questionnaire at ages 7, 12, 24 months, and 6-7 years. Children with parents-report of an itchy rash, which was coming and going in the last 12 months (or since the last follow-up in the first year of life regardless of duration) and first appeared before the age of 5 years, were regarded as having developed eczema. Children with only a diaper rash, rash around the eyes, and/or scalp scaling were not regarded as having developed eczema. 'AD' at the age of 24 months was defined according to the UK-Working Party Criteria [17] as scored during home-visits by a trained research-nurse. Children with UK-Working Party probability score of $>0.9$ were considered as having AD.

At the age of 24 months, venous blood samples were taken to determine total IgE and specific IgE against hen's egg, cow's milk, peanut, birch, grass pollen, cat, dog, and house dust mite, measured as described earlier [18]. Detection limits for specific and total IgE were 0.10 and $0.50 \mathrm{IU} /$ $\mathrm{mL}$, respectively. 'Allergic sensitization' was considered to be present if specific serum IgE levels were $>0.30 \mathrm{IU} / \mathrm{mL}$ against at least one of the allergens tested. Total serum IgE was considered 'high' above the 67th percentile within the total cohort, resulting in a cut-off value of $25 \mathrm{IU} / \mathrm{mL}$.

\section{Definition of confounders}

The following potential confounders were included in the model: recruitment group (conventional, alternative), age of the mother at the estimated date of delivery, maternal ethnicity, maternal education level, maternal smoking during pregnancy, parental history of atopy and/or asthma, presence of older siblings (specified for sibling atopy), term of gestation, season of birth, gender, birth weight, mode of delivery, child exposure to environmental tobacco smoke, breastfeeding, child day care, and pets at home.

\section{Statistical analysis}

Statistical analyses were performed using the statistical software package SPSS 15.0 for Windows (SPSS Inc., Chicago, IL, USA). Fatty acids of interest were categorized into five categories based on the quintile distribution within the total cohort. Logistic regression models were used for analyses of association between the various maternal fatty acid quintiles (using the first quintile as reference) and atopic manifestations in offspring that were only measured at single points in time. Generalized estimating equations (GEE) models with an exchangeable correlation structure were used to investigate the longitudinal effects of maternal fatty acid status on offspring wheeze and eczema until age 6-7 years, taking dependency between repeated measurements in the same individual into account. We tested if the association between maternal fatty acids and child outcomes differed with increasing age in the GEE analysis by including an interaction term with age. Age was coded 1 through 6 for each follow-up moment for wheeze, 1 through 4 for eczema. $P$-values $<0.05$ were considered statistically significant. Results are presented as adjusted odds ratios (OR) (adjusted for all previously mentioned potential confounders) with corresponding 95\% confidence intervals.

\section{Results}

\section{Study population}

In 1356 of the 2834 mothers included in the KOALA study, maternal fatty acid status in pregnancy was determined (Fig. 1). After applying our exclusion criteria, 1275 mother-infant pairs remained for analysis. At age 6-7 years, questionnaires were available for 951 children, giving a response rate for this age of $74.6 \%$.

Table 1 shows the main characteristics of the study population. There were no large differences in background characteristics between participants at baseline and participants who completed the 24-month home-visit or the 6-7-year follow-up questionnaire.

\section{Maternal fatty acid status}

Table 2 shows mean values and standard deviation of each fatty acid. No significant differences were found between atopic and non-atopic mothers in the level of the individual fatty acids, sum of n-6 LCPs or n-3 LCPs, ratio of LA to ALA, and ratio of n-6 to n-3 LCPs. 


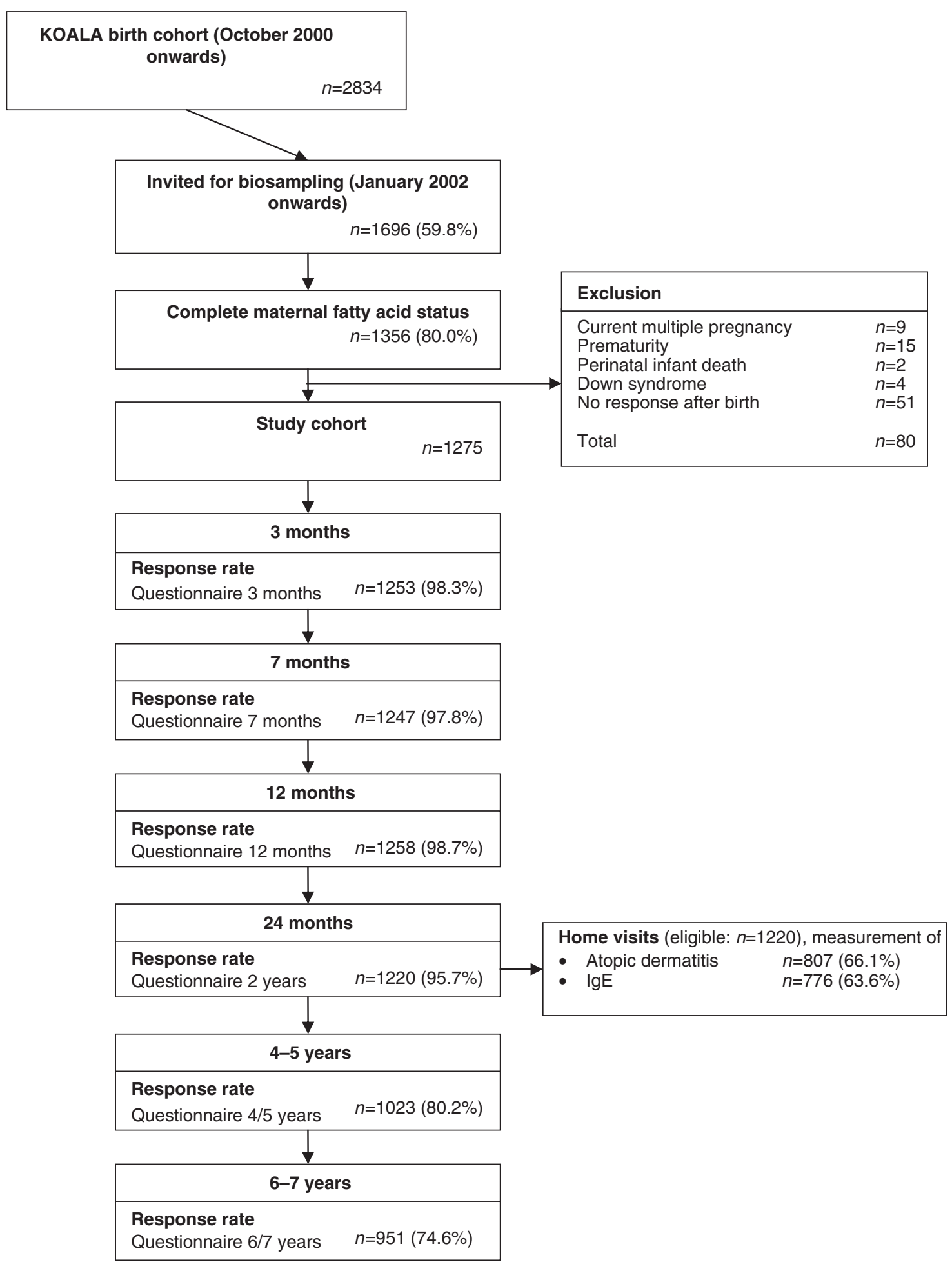

Fig. 1. Flowchart for inclusion in study cohort and response rates at each follow-up moment until age 6-7 years.

\section{Atopic outcomes}

Wheezing was the most frequently reported symptom in the first year of life (28.9\%), but declined with increasing age. Similar trend was seen for the presence of parentally reported eczema (supporting information Fig. S1).
At age 24 months, 111 (13.8\%) children were found to have $\mathrm{AD}$ according to the UK-Working Party Criteria. Allergic sensitization was present in 213 (27.7\%) children. At 6-7 years of age, asthma was present in $6.7 \%$ and allergic rhinoconjunctivitis in $7.3 \%$ of the children. 
Table 1. Population characteristics

\begin{tabular}{|c|c|c|c|}
\hline & $\begin{array}{l}\text { Baseline } \\
(n=1275)\end{array}$ & $\begin{array}{l}\text { Home visit } \\
(n=807)\end{array}$ & $\begin{array}{l}\text { 6-7-year follow-up } \\
(n=951)\end{array}$ \\
\hline \multicolumn{4}{|l|}{ Recruitment group, $n(\%)$} \\
\hline Conventional & $915(71.8)$ & $574(71.1)$ & $679(71.4)$ \\
\hline Maternal age (years), mean (SD) & $32.6(3.8)$ & $32.8(3.9)$ & $32.7(3.8)$ \\
\hline \multicolumn{4}{|l|}{ Maternal education level, $n(\%)$} \\
\hline Low & $94(7.4)$ & $60(7.4)$ & $60(6.3)$ \\
\hline Middle & $439(34.4)$ & $275(34.1)$ & $310(32.6)$ \\
\hline High & $691(54.2)$ & $440(54.5)$ & $546(57.4)$ \\
\hline Different & $39(3.1)$ & $25(3.1)$ & $23(2.4)$ \\
\hline Unknown & $12(0.9)$ & $7(0.9)$ & $12(1.3)$ \\
\hline \multicolumn{4}{|l|}{ Maternal ethnicity, $n(\%)$} \\
\hline Dutch & $1228(96.3)$ & 774 (95.9) & $916(96.3)$ \\
\hline \multicolumn{4}{|l|}{ Maternal smoking during pregnancy, $n(\%)$} \\
\hline Yes & $57(4.5)$ & $37(4.6)$ & $33(3.5)$ \\
\hline \multicolumn{4}{|l|}{ Parental atopy, $n(\%)$} \\
\hline Parents not atopic & $505(39.6)$ & $328(40.6)$ & $382(40.2)$ \\
\hline Mother atopic & $290(22.7)$ & $183(22.7)$ & $207(21.8)$ \\
\hline Father atopic & $290(22.7)$ & $178(22.1)$ & $211(22.2)$ \\
\hline Both atopic & $180(14.2)$ & $116(14.4)$ & $145(15.2)$ \\
\hline Unknown & $10(0.8)$ & $2(0.2)$ & $6(0.6)$ \\
\hline \multicolumn{4}{|l|}{ Atopy in older siblings, $n(\%)$} \\
\hline No siblings & $520(40.8)$ & 307 (37.9) & $397(41.7)$ \\
\hline$\geqslant 1$ sibling, none atopic & $527(41.3)$ & $351(43.5)$ & $386(40.6)$ \\
\hline$\geqslant 1$ sibling, at least one atopic & $228(17.9)$ & $150(18.6)$ & $168(17.7)$ \\
\hline Term of gestation (weeks), mean (SD) & $39.7(1.2)$ & $39.7(1.2)$ & $39.7(1.1)$ \\
\hline \multicolumn{4}{|l|}{ Season of birth, $n(\%)$} \\
\hline Winter & $376(29.5)$ & $236(29.2)$ & $286(30.1)$ \\
\hline Spring & $318(24.9)$ & $203(25.2)$ & $229(24.1)$ \\
\hline Summer & $285(22.3)$ & $186(23.0)$ & $212(21.3)$ \\
\hline Autumn & $296(23.2)$ & $182(22.6)$ & $224(23.6)$ \\
\hline \multicolumn{4}{|l|}{ Gender, $n(\%)$} \\
\hline Male & $641(50.3)$ & 417 (51.7) & $480(50.5)$ \\
\hline Birth weight (grams), mean (SD) & $3569(472)$ & $3574(474)$ & $3579(467)$ \\
\hline \multicolumn{4}{|l|}{ Mode of delivery, $n(\%)$} \\
\hline Home birth & $581(45.6)$ & $365(45.2)$ & $441(46.4)$ \\
\hline Hospital birth - vaginal & $527(41.3)$ & $338(41.9)$ & $389(40.9)$ \\
\hline Hospital birth - caesarean & $141(11.1)$ & $92(11.4)$ & $107(11.3)$ \\
\hline Unknown & $26(2.0)$ & $12(1.5)$ & $14(1.5)$ \\
\hline \multicolumn{4}{|l|}{ Environmental tobacco smoke $0-2$ years, $n(\%)$} \\
\hline Never & $449(35.2)$ & $289(35.8)$ & $346(36.4)$ \\
\hline Seldom & $686(53.8)$ & $432(53.5)$ & $510(53.6)$ \\
\hline Regular & $140(11.0)$ & $86(10.7)$ & $95(10.0)$ \\
\hline \multicolumn{4}{|l|}{ Breastfeeding, $n(\%)$} \\
\hline Exclusively BF at 3 months & $617(48.4)$ & $388(48.1)$ & $473(49.7)$ \\
\hline Combination BF and formula at 3 months & 203 (15.9) & $135(16.7)$ & $156(16.4)$ \\
\hline Stopped BF before 3 months & $273(21.4)$ & $163(20.2)$ & $206(21.7)$ \\
\hline Never BF & $158(12.4)$ & $110(13.6)$ & $104(10.9)$ \\
\hline Unknown & $24(1.9)$ & $11(1.4)$ & $12(1.3)$ \\
\hline \multicolumn{4}{|l|}{ Child day care attendance, $n(\%)$} \\
\hline Any child day care at 24 months & $859(67.4)$ & $555(68.8)$ & $652(68.6)$ \\
\hline \multicolumn{4}{|l|}{ Pets at home, $n(\%)^{*}$} \\
\hline Any pets at 24 months & $639(50.1)$ & 395 (48.9) & 456 (47.9) \\
\hline Unknown & $53(4.2)$ & $24(3.0)$ & $23(2.4)$ \\
\hline
\end{tabular}

*Exposure to dogs, cats, birds, rodents, or any other furry animals at home until the age of 24 months. 
Table 2. Maternal fatty acid status at 34-36 weeks of pregnancy

\begin{tabular}{lcc}
\hline & $\begin{array}{l}\text { Non-atopic } \\
\text { mothers } \\
(n=805)\end{array}$ & $\begin{array}{l}\text { Atopic } \\
\text { mothers } \\
(n=470)\end{array}$ \\
\hline n-6 PUFAs & $20.98(2.30)$ & $21.08(2.23)$ \\
LA & $3.43(0.59)$ & $3.39(0.58)$ \\
DGLA & $7.57(1.30)$ & $7.46(1.23)$ \\
AA & $11.00(1.43)$ & $10.85(1.40)$ \\
Sum n-6 LCPs & & \\
n-3 PUFAs & $0.28(0.09)$ & $0.28(0.09)$ \\
ALA & $0.43(0.28)$ & $0.42(0.30)$ \\
EPA & $0.54(0.13)$ & $0.52(0.14)$ \\
DPA & $3.88(0.84)$ & $3.84(0.89)$ \\
DHA & $4.84(1.09)$ & $4.79(1.17)$ \\
Sum n-3 LCPs & & \\
n-6 to n-3 ratio & $83.40(30.80)$ & $83.56(27.70)$ \\
Ratio LA to ALA & $2.38(0.53)$ & $2.38(0.58)$ \\
Ratio n-6 LCPs to n-3 LCPs &
\end{tabular}

Maternal atopy was defined as self-reported seasonal rhinoconjunctivitis (hayfever) or doctor's diagnosed atopic eczema, aeroallergen allergy, or bronchial asthma. Values are means and standard deviation (SD) in weight percentage of total fatty acids present.

PUFA, polyunsaturated fatty acid; LA, linoleic acid; AA, arachidonic acid; LCP, long-chain polyunsaturated fatty acid; ALA, $\alpha$-linolenic acid; EPA, eicosapentaenoic acid; DPA, docosapentenoic acid; DHA, docosahexaenoic acid.

\section{Maternal fatty acid status and childhood atopic outcomes}

Airway manifestations. Parentally reported wheeze in the first 6-7 years of life was not associated with maternal fatty acid status in pregnancy (logistic regression with GEE, Table 3). Interaction with age was not statistically significant for all fatty acids tested in the analyses of wheeze. In addition to analyses for wheeze, we found no association between maternal fatty acid status and development of asthma at age 6-7 years (Table 3) or allergic rhinoconjunctivitis at 6-7 years (supporting information Table S1). However, a tendency for higher OR for developing asthma at 6-7 years with an increasing n-6 to n-3 LCP ratio was found, but did not reach statistical significance.

Skin manifestations. Risk of eczema during the first 6-7 years of life decreased with increasing n-6 to n-3 LCPs ratio, with the lowest risk in the highest quintile [OR 0.60 (0.42-0.87), $P$ for trend over the quintiles 0.012, Table 3]. For AA, and not the other fatty acids tested, we found a statistically significant interaction with age $(P 0.033)$, and Fig. 2 shows the change of the risk of eczema by age, expressed as adjusted OR for an increment of one quintile of maternal AA from the longitudinal GEE analysis. The risk of parentally reported eczema in the first 7 months of life decreased with increasing levels of AA [OR 0.88 (0.79-0.97), $P$ for trend over the quintiles 0.013]. For eczema at 12 months of age, a modest protective effect of
AA was also shown [OR 0.92 (0.85-0.99), $P$ for trend over the quintiles 0.048]. We found no association between AA and eczema later in life. OR for eczema tended to increase with increasing levels of n-3 LCPs, but without reaching statistical significance.

We found no association between any of the individual fatty acids or ratios and the presence of $\mathrm{AD}$ at 24 months (supporting information Table S2).

Allergic sensitization and total immunoglobulin E. Maternal fatty acid status in pregnancy was not associated with presence of allergic sensitization or high total IgE at age 24 months (supporting information Tables S3 and S4).

\section{Discussion}

In this population-based birth cohort study, we found that higher exposure to n-6 vs. n-3 LCPs in utero unexpectedly was associated with a reduced risk of developing eczema, with strongest effects of AA found in early childhood. By contrast, higher exposure to n-6 vs. n-3 LCPs was not clearly associated with airway manifestations of atopic diseases, or with sensitization or high total IgE at 24 months.

The observations regarding eczema seem contrary to what might be expected from current knowledge on the role of fatty acids in the formation of inflammatory mediators and allergy. The absence of effect for the other atopic manifestations raises questions about differences in pathogenesis between the various atopic disorders.

Our results are in line with result from the Melbourne Atopy Cohort Study, which showed that high levels of n-3 LCPs in colostrum and breast milk are associated with increased risk of atopic eczema [19]. However, we could not confirm their finding of an increased risk of sensitization, measured by skin prick tests [20]. Other studies of fatty acid content in breast milk and atopic outcomes have shown mixed results [21-27], but three of them showed a decreased risk of eczema associated with higher levels of n-3 LCPs in breast milk [21, 26, 27].

To our knowledge, only two earlier studies examined the association between maternal fatty acids in pregnancy and clinical atopic symptoms in their offspring. In a small study population (47 mother-child pairs), Yu and Björksten [28] found no clear relation between maternal serum fatty acids at time of delivery and atopic outcomes in the offspring until 6 years of age. However, they also studied correlations of fatty acids between mother's serum and cord blood, and noticed that some of these correlations were different for children with and without allergy [e.g. the correlation between maternal serum DGLA and cord blood AA was $r=0.65(P=0.001, n=22)$ if the child had allergy and $r=0.16(P>0.05, n=25)$ if the child had no allergy]. From this, the authors inferred that atopy is associated with a disturbed fatty acid metabolism. 
Table 3. Association between maternal fatty acids in plasma phospholipids in pregnancy and atopic outcomes in the child

\begin{tabular}{|c|c|c|c|c|}
\hline & \multirow[b]{2}{*}{ Range (wt\%) } & \multicolumn{3}{|l|}{ Adjusted OR $(95 \% \mathrm{CI})^{\ddagger}$} \\
\hline & & $\begin{array}{l}\text { Wheeze from birth to } \\
\text { age } 6-7 \text { years }(n=1275)^{*}\end{array}$ & $\begin{array}{l}\text { Asthma at age } 6-7 \text { years } \\
(n=951)^{\dagger}\end{array}$ & $\begin{array}{l}\text { Eczema from birth to } \\
\text { age } 6-7 \text { years }(n=1275)^{*}\end{array}$ \\
\hline \multicolumn{5}{|l|}{ n-6 PUFAs } \\
\hline \multicolumn{5}{|l|}{ AA } \\
\hline 1 & $\leqslant 6.46$ & 1 (reference) & 1 (reference) & 1 (reference) \\
\hline 2 & $6.47-7.15$ & $1.23(0.87-1.73)$ & $1.69(0.70-4.10)$ & $0.94(0.67-1.31)$ \\
\hline 3 & $7.16-7.85$ & $1.08(0.78-1.50)$ & $1.29(0.52-3.20)$ & $1.03(0.73-1.44)$ \\
\hline 4 & $7.86-8.60$ & $1.08(0.78-1.49)$ & $0.82(0.31-2.15)$ & $0.77(0.55-1.09)$ \\
\hline 5 & $\geqslant 8.61$ & $1.03(0.74-1.44)$ & $1.70(0.67-4.33)$ & $0.81(0.56-1.15)$ \\
\hline$P$ for trend ${ }^{\S}$ & & 0.80 & 0.83 & 0.12 \\
\hline \multicolumn{5}{|l|}{ n-3 PUFAs } \\
\hline \multicolumn{5}{|l|}{ n-3 LCPs } \\
\hline 1 & $\leqslant 3.93$ & 1 (reference) & 1 (reference) & 1 (reference) \\
\hline 2 & $3.94-4.44$ & $0.96(0.70-1.31)$ & $1.85(0.83-4.12)$ & $1.21(0.85-1.73)$ \\
\hline 3 & $4.45-4.93$ & $1.12(0.82-1.53)$ & $1.12(0.45-2.71)$ & $1.02(0.71-1.47)$ \\
\hline 4 & $4.94-5.64$ & $1.15(0.85-1.57)$ & $0.92(0.37-2.29)$ & $1.30(0.91-1.85)$ \\
\hline 5 & $\geqslant 5.65$ & $0.98(0.70-1.37)$ & $0.85(0.34-2.16)$ & $1.29(0.91-1.83)$ \\
\hline$P$ for trend & & 0.69 & 0.33 & 0.15 \\
\hline \multicolumn{5}{|l|}{$n-6$ to $n-3$ ratio } \\
\hline \multicolumn{5}{|c|}{ Ratio LA to ALA } \\
\hline 1 & $\leqslant 60.72$ & 1 (reference) & 1 (reference) & 1 (reference) \\
\hline 2 & 60.73-72.35 & $1.04(0.76-1.42)$ & $1.14(0.51-2.55)$ & $1.04(0.73-1.47)$ \\
\hline 3 & $72.36-82.29$ & $0.87(0.64-1.19)$ & $0.55(0.21-1.45)$ & $1.12(0.80-1.57)$ \\
\hline 4 & 83.30-102.69 & $0.90(0.66-1.23)$ & $1.08(0.47-2.49)$ & $0.83(0.58-1.19)$ \\
\hline 5 & $\geqslant 102.70$ & $0.91(0.68-1.23)$ & $0.60(0.23-1.56)$ & $0.94(0.66-1.34)$ \\
\hline$P$ for trend & & 0.35 & 0.31 & 0.40 \\
\hline \multicolumn{5}{|c|}{ Ratio n-6 LCPs to n-3 LCPs } \\
\hline 1 & $\leqslant 1.91$ & 1 (reference) & 1 (reference) & 1 (reference) \\
\hline 2 & $1.92-2.24$ & $0.88(0.63-1.23)$ & $1.12(0.43-2.89)$ & $0.72(0.51-1.00)$ \\
\hline 3 & $2.25-2.52$ & $1.03(0.75-1.42)$ & $1.47(0.56-3.85)$ & $0.68(0.49-0.96)$ \\
\hline 4 & $2.53-2.84$ & $0.83(0.59-1.18)$ & $2.07(0.82-5.24)$ & $0.70(0.49-0.98)$ \\
\hline 5 & $\geqslant 2.85$ & $0.97(0.70-1.35)$ & $1.87(0.76-4.63)$ & $0.60(0.42-0.87)$ \\
\hline$P$ for trend & & 0.82 & 0.08 & 0.012 \\
\hline
\end{tabular}

Odds ratios (ORs) and 95\% confidence intervals (95\% CI) for the association between maternal fatty acids in plasma phospholipids in pregnancy (in quintiles) and parentally reported atopic outcomes.

*Wheeze and eczema repeatedly measured between birth and 6-7 years of age and analysed using generalized estimating equation (GEE) models. Number of cases wheeze at 3 months of age 151/1253, 7 months 146/1247, 12 months 204/1258, 24 months 190/1220, 4-5 years 98/1023, 6-7 years 73/951; number of cases eczema at 7 months of age 204/1247, 12 months 168/1258, 24 months 281/1220, 6-7 years 142/951.

${ }^{\dagger}$ Asthma at 6-7 years of age analysed using logistic regression models. Number of cases of asthma at 6-7 years of age 64/951.

${ }^{\ddagger}$ Adjusted for recruitment group, maternal age, maternal ethnicity, maternal education level, maternal smoking during pregnancy, parental history of atopy, term of gestation, season of birth, gender, birth weight, mode of delivery, exposure to environmental tobacco, presence of older siblings and sibling atopy, breastfeeding, child day care, and pets at home.

${ }^{\S}$ Test for trend over quintiles (coded 1 through 5).

The ALSPAC Study Team [29] found a weak positive association between the AA : EPA ratio in cord blood and eczema in children aged 18-30 months. This was not found for the ratio in maternal blood, measured in erythrocyte membrane phospholipids from 20 weeks of pregnancy onwards (while we measured fatty acids in plasma phospholipids around 36 weeks of pregnancy). Fatty acid concentrations measured in plasma mainly reflect dietary intake and fatty acid metabolism on shorter term (days or weeks) than concentrations measured in the erythrocyte membrane (months) [30], so that our measurement mainly represents fetal fatty acid exposure in the last trimester of pregnancy. The authors from the ALSPAC study concluded that it seems unlikely that fetal exposure to n-6 and n-3 fatty acids is an important determinant of early childhood wheezing and atopic disease [29]. Neither the ALSPAC study nor our study therefore supports the hypothesis of Black and 


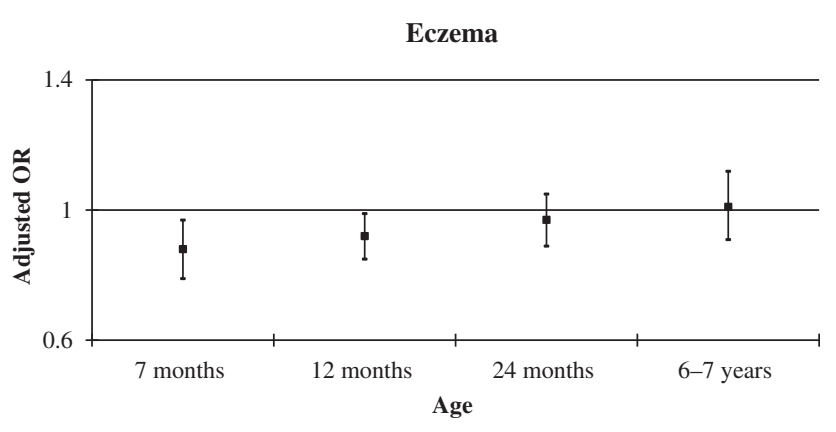

Fig. 2. Longitudinal association between arachidonic acid in maternal plasma phospholipids in pregnancy and risk of eczema in the child. Result from logistic regression using a generalized estimating equation (GEE) model with an interaction term for age, for eczema as repeated measured outcome (number of cases of eczema at 7 months of age 204/ 1247, 12 months 168/1258, 24 months 281/1220, 6-7 years 142/951). Odds ratios (OR) are adjusted for recruitment group, maternal age, maternal ethnicity, maternal education level, maternal smoking during pregnancy, parental history of atopy, term of gestation, season of birth, gender, birth weight, mode of delivery, exposure to environmental tobacco, presence of older siblings and sibling atopy, breastfeeding, child day care, and pets at home. Vertical bars represent 95\% confidence intervals. The $P$-value for the age interaction was 0.033 .

Sharpe [2] that atopic diseases are due to an increased n-6/n-3 ratio.

Nevertheless, our observations concerning eczema suggest that n-6 and n-3 LCPs indeed have a prenatal effect with clinical relevance. The absence of a clear effect for the airway-related manifestations of atopic disease at 6-7 years could possibly be explained by our observation that the effect of fatty acid exposure in pregnancy appeared to be strongest in early childhood. Wheeze symptoms in the first year of life are associated with viral upper airway infections, resulting in an overrepresentation of non-atopic wheeze [31]. Overrepresentation of non-atopic manifestations might also explain the unexpected protective influence of higher n- 6 to n-3 LCPs on parentally reported eczema in our study. This is supported by the fact that we could not confirm the results for $\mathrm{AD}$, the objectified measurement of atopic eczema at 24 months. On the other hand, the prevalence of eczema peaks around 12 months and shows a relapsing-remitting pattern, which could mean that we missed many cases of flexural dermatitis at the time of home-visits due to the single measurement of $\mathrm{AD}$, remission, or successful therapy [32].

Our finding that high maternal AA status is associated with lower risk of eczema suggests that other dietary factors than fish (oil) are also implicated; for example, by a negative influence of trans fatty acids on LCP concentrations and their confounding on health outcomes in the child, as suggested earlier [33, 34]. Alternatively, it may be a marker of genetic variants in the fatty acid metabolism (for instance the FADS gene cluster determining desaturation, Elovl2 determining elongation, or fatty acid transport and binding proteins, FATP, and FABP). Schaeffer et al. [35] have shown an association between common variants in FADS gene cluster and allergic rhinoconjunctivitis. Genetic differences in FABP could perhaps also explain the absence of a relation with maternal n-3 LCPs in the present study. During pregnancy, n-3 LCPs, especially DHA, are preferentially transported to the fetus at the expense of maternal DHA status through an active mechanism involving placental fatty acidbinding protein [36]. We speculate that fish (oil) supply to the fetus is not reflected very well in maternal n-3 LCPs in plasma phospholipids because of this preferential transport.

\section{Strengths and limitations}

The present study has several methodological strengths. In this large birth cohort study, data have been collected prospectively. Besides, we used repeated questionnaires with relatively short time-intervals (reducing the influence of recall bias) to determine parentally reported atopic manifestations and potential confounders, in combination with laboratory measurements that offer objective characterization of both exposure and atopic outcomes. The duration of follow-up together with high response rates gives opportunities to examine the full spectrum of atopic disorders.

Our study has some limitations. First, missing data due to non-response could have influenced our results. However, bias is very unlikely because we had high follow-up rates and the distribution of population characteristics at 6-7-year follow-up was roughly similar to those at baseline. Confounding-by-indication is a potential hazard in observational studies; mothers with a personal or family history of atopy may use fish oil supplements to treat or prevent their own or future child's atopic symptoms, while the child has a genetically enhanced risk of atopy. It is very unlikely that this possible confounding influenced our results because maternal, paternal, and sibling's history of atopic disorders were included in the multivariate analyses. In addition, the use of fish oil supplementation during pregnancy was not associated with reported parental atopy in our data (not presented). We measured fatty acids in phospholipids from single blood sample at the end of pregnancy; we cannot be sure that this reflects maternal fatty acid status during the whole pregnancy [30]. As a further limitation, assessment of wheeze and eczema relied on written questionnaires based on ISAAC questions, which have been validated for children aged 5-6 years but not in younger children. The UK Working Party Criteria used for the identification of $\mathrm{AD}$ around 24 months of age are also not validated for this 
age group, except for the key symptom of flexural dermatitis [37]. Finally, there were not enough children with symptoms to be able to differentiate between different degrees of symptom severity, while earlier research suggested that DHA supplementation directly to the child mainly acts on severity of symptoms in at least $\mathrm{AD}$, and not just at prevalence [38].

\section{Conclusion}

We conclude that development of eczema in childhood is inversely associated with prenatal exposure to $n-6$ vs. $n-3$ fatty acids, with strongest effects of AA in early childhood. The underlying mechanisms are not clear and require further study, especially for the influence of amount and source of maternal (trans) fatty acids intake, and genetic variants in fatty acid metabolism.

\section{Acknowledgements}

This work was financially supported by the Netherlands Organization for Health Research and Development (ZonMw Prevention Program 1.210-00-090), the Netherlands Asthma Foundation (grant nos. 3.2.303.48 and 3.2.07.022), Royal Friesland Foods (Leeuwarden, the Netherlands), Phoenix Foundation (the Netherlands), Raphaël Foundation (the Netherlands), Iona Foundation (the Netherlands), Foundation for the Advancement of Heilpedagogie (the Netherlands), Triodos Foundation (Driebergen, the Netherlands), and the Netherlands Ministry of Public Health, Welfare, and Sport.

\section{References}

1 Asher MI, Montefort S, Bjorksten B et al. Worldwide time trends in the prevalence of symptoms of asthma, allergic rhinoconjunctivitis, and eczema in childhood: ISAAC Phases One and Three repeat multicountry cross-sectional surveys. Lancet 2006; 368:733-43.

2 Black PN, Sharpe S. Dietary fat and asthma: is there a connection? Eur Respir J 1997; 10:6-12.

3 Calder PC. Polyunsaturated fatty acids, inflammation, and immunity. Lipids 2001; 36:1007-24.

4 Calder PC, Miles EA. Fatty acids and atopic disease. Pediatr Allergy Immunol 2000; 11 (Suppl. 13):29-36.

5 Prescott SL, Calder PC. N-3 polyunsaturated fatty acids and allergic disease. Curr Opin Clin Nutr Metab Care 2004; 7:123-9.

6 Devereux G, Seaton A. Diet as a risk factor for atopy and asthma. J Allergy Clin Immunol 2005; 115:1109-17; quiz 18.

7 Sala-Vila A, Miles EA, Calder PC. Fatty acid composition abnormalities in atopic disease: evidence explored and role in the disease process examined. Clin Exp Allergy 2008; 38:1432-50.

8 Miyake Y, Sasaki S, Arakawa M, Tanaka K, Murakami K, Ohya Y. Fatty acid intake and asthma symptoms in Japanese children: the Ryukyus Child Health Study. Clin Exp Allergy 2008; 38:1644-50.

9 Woods RK, Thien FC, Abramson MJ. Dietary marine fatty acids (fish oil) for asthma in adults and children. Cochrane Database Syst Rev 2002: CD001283.
10 Warner JA, Jones CA, Jones AC, Warner JO. Prenatal origins of allergic disease. J Allergy Clin Immunol 2000; 105 (Part 2):S493-8.

11 Prescott SL, Dunstan JA. Prenatal fatty acid status and immune development: the pathways and the evidence. Lipids 2007; 42:801-10.

12 Kummeling I, Thijs C, Penders J et al. Etiology of atopy in infancy: the KOALA Birth Cohort Study. Pediatr Allergy Immunol 2005; 16:679-84.

13 Bastiaanssen JM, de Bie RA, Bastiaenen $\mathrm{CH}$ et al. Etiology and prognosis of pregnancy-related pelvic girdle pain; design of a longitudinal study. BMC Public Health 2005; 5:1.

14 The International Study of Asthma and Allergies in Childhood (ISAAC) Steering Committee. Worldwide variation in prevalence of symptoms of asthma, allergic rhinoconjunctivitis, and atopic eczema. Lancet 1998; 351:1225-32.

15 Bindels PJ, Grol MH, Ponsioen BP, Salome PL, Wiersma T, Goudswaard AN. Summary of the practice guideline 'asthma in children' (second revision) from the Dutch College of General Practitioners. Ned Tijdschr Geneeskd 2008; 152:550-5.

16 van Balen JA, Verduijn MM, Sachs AP et al. Summary of the practice guideline 'allergic and non-allergic rhinitis' (first revision) from the Dutch College of General Practitioners. Ned Tijdschr Geneeskd 2007; 151:2261-5.

17 Williams HC, Burney PG, Pembroke AC, Hay RJ. Validation of the U.K. diagnostic criteria for atopic dermatitis in a population setting. U.K. Diagnostic Criteria for
Atopic Dermatitis Working Party. $\mathrm{Br} \mathrm{J}$ Dermatol 1996; 135:12-7.

18 Kummeling I, Thijs C, Huber $\mathrm{M}$ et al. Consumption of organic foods and risk of atopic disease during the first 2 years of life in the Netherlands. $\mathrm{Br} J \mathrm{Nutr}$ 2008; 99:598-605.

19 Lowe AJ, Thien FC, Stoney RM et al. Associations between fatty acids in colostrum and breast milk and risk of allergic disease. Clin Exp Allergy 2008; 38:1745-51.

20 Stoney RM, Woods RK, Hosking CS, Hill DJ, Abramson MJ, Thien FC. Maternal breast milk long-chain n-3 fatty acids are associated with increased risk of atopy in breastfed infants. Clin Exp Allergy 2004; 34:194-200.

21 Wijga AH, van Houwelingen AC, Kerkhof $\mathrm{M}$ et al. Breast milk fatty acids and allergic disease in preschool children: the prevention and incidence of asthma and mite allergy birth cohort study. $J$ Allergy Clin Immunol 2006; 117:440-7.

22 Reichardt P, Muller D, Posselt U et al. Fatty acids in colostrum from mothers of children at high risk of atopy in relation to clinical and laboratory signs of allergy in the first year of life. Allergy 2004; 59:394-400.

23 Hoppu U, Rinne M, Lampi AM, Isolauri E. Breast milk fatty acid composition is associated with development of atopic dermatitis in the infant. $J$ Pediatr Gastroenterol Nutr 2005; 41:335-8.

24 Kankaanpaa P, Nurmela K, Erkkila A et al. Polyunsaturated fatty acids in maternal diet, breast milk, and serum lipid fatty acids of infants in relation to atopy. Allergy 2001; 56:633-8. 
25 Laitinen K, Sallinen J, Linderborg K, Isolauri E. Serum, cheek cell and breast milk fatty acid compositions in infants with atopic and non-atopic eczema. Clin Exp Allergy 2006; 36:166-73.

26 Oddy WH, Pal S, Kusel MM et al. Atopy, eczema and breast milk fatty acids in a high-risk cohort of children followed from birth to 5 yr. Pediatr Allergy Immunol 2006; 17:4-10.

27 Thijs C, Müller A, Rist L et al. Fatty acids in breast milk and development of atopic eczema and allergic sensitisation in infancy. Allergy 2010, doi: 10.1111/j.13989995.2010.02445.x.

28 Yu G, Björksten B. Serum levels of phospholipid fatty acids in mothers and their babies in relation to allergic disease. Eur J Pediatr 1998; 157:298-303.

29 Newson RB, Shaheen SO, Henderson AJ, Emmett PM, Sherriff A, Calder PC. Umbilical cord and maternal blood red cell fatty acids and early childhood wheezing and eczema. J Allergy Clin Immunol 2004; 114:531-7.
30 Hodson L, Skeaff CM, Fielding BA. Fatty acid composition of adipose tissue and blood in humans and its use as a biomarker of dietary intake. Prog Lipid Res 2008; 47:348-80.

31 Henderson J, Granell R, Heron $\mathrm{J}$ et al. Associations of wheezing phenotypes in the first 6 years of life with atopy, lung function and airway responsiveness in mid-childhood. Thorax 2008; 63:974-80.

32 Rance F, Boguniewicz M, Lau S. New visions for atopic eczema: an iPAC summary and future trends. Pediatr Allergy Immunol 2008; 19 (Suppl. 19):17-25.

33 Szabo E, Boehm G, Beermann C et al. Trans octadecenoic acid and trans octadecadienoic acid are inversely related to long-chain polyunsaturates in human milk: results of a large birth cohort study. Am J Clin Nutr 2007; 85:1320-6.

34 Decsi T. Nutritional relevance of trans isomeric fatty acids in human milk. Acta Paediatr 2003; 92:1369-71.

35 Schaeffer L, Gohlke H, Muller M et al. Common genetic variants of the FADS1
FADS2 gene cluster and their reconstructed haplotypes are associated with the fatty acid composition in phospholipids. Hum Mol Genet 2006; 15:1745-56.

36 Hanebutt FL, Demmelmair H, Schiessl B, Larque E, Koletzko B. Long-chain polyunsaturated fatty acid (LC-PUFA) transfer across the placenta. Clin Nutr 2008; 27:685-93.

37 Fleming S, Bodner C, Devereux G et al. An application of the United Kingdom Working Party diagnostic criteria for atopic dermatitis in Scottish infants. $J$ Invest Dermatol 2001; 117:1526-30.

38 Koch C, Dolle S, Metzger M et al. Docosahexaenoic acid (DHA) supplementation in atopic eczema: a randomized, double-blind, controlled trial. $\mathrm{Br} J \mathrm{Der}$ matol 2008; 158:786-92.

\section{Supporting Information}

Additional Supporting Information may be found in the online version of this article:

Figure S1. Prevalence of wheeze and eczema (of available cases) at different ages.

Table S1. Association between maternal fatty acids in plasma phospholipids in pregnancy and allergic rhinoconjunctivitis in the child at age 6-7 years.

Table S2. Association between maternal fatty acids in plasma phospholipids in pregnancy and atopic dermatitis in the child at age 24 months.
Table S3. Association between maternal fatty acids in plasma phospholipids in pregnancy and sensitization in the child at age 24 months.

Table S4. Association between maternal fatty acids in plasma phospholipids in pregnancy and high total IgE in the child at age 24 months.

Please note: Wiley-Blackwell is not responsible for the content or functionality of any supporting materials supplied by the authors. Any queries (other than missing material) should be directed to the corresponding author for the article. 